\title{
Review Article \\ Electrochemical Techniques in Textile Processes and Wastewater Treatment
}

\author{
Mireia Sala and M. Carmen Gutiérrez-Bouzán \\ Institut d'Investigació Tèxtil i Cooperació Industrial de Terrassa (INTEXTER), \\ Universitat Politècnica de Catalunya (UPC), C/Colom 15, 08222 Terrassa, Spain \\ Correspondence should be addressed to Mireia Sala, mireia.sala@intexter.upc.edu
}

Received 22 March 2012; Revised 27 July 2012; Accepted 29 July 2012

Academic Editor: Jiaguo Yu

Copyright ( 2012 M. Sala and M. C. Gutiérrez-Bouzán. This is an open access article distributed under the Creative Commons Attribution License, which permits unrestricted use, distribution, and reproduction in any medium, provided the original work is properly cited.

The textile industry uses the electrochemical techniques both in textile processes (such as manufacturing fibers, dyeing processes, and decolorizing fabrics) and in wastewaters treatments (color removal). Electrochemical reduction reactions are mostly used in sulfur and vat dyeing, but in some cases, they are applied to effluents discoloration. However, the main applications of electrochemical treatments in the textile sector are based on oxidation reactions. Most of electrochemical oxidation processes involve indirect reactions which imply the generation of hypochlorite or hydroxyl radical in situ. These electrogenerated species are able to bleach indigo-dyed denim fabrics and to degrade dyes in wastewater in order to achieve the effluent color removal. The aim of this paper is to review the electrochemical techniques applied to textile industry. In particular, they are an efficient method to remove color of textile effluents. The reuse of the discolored effluent is possible, which implies an important saving of salt and water (i.e., by means of the "UVEC Cell").

\section{Introduction}

Traditionally, the electrochemical techniques have been used for the synthesis of compounds or for metal recovery treatments. But more recently, a wide range of other applications have been proposed. Some of them are proposed to solve several technical problems of the textile industry. This is the case of a recent application to produce smart textiles [1-28] by obtaining functionalized fabrics. These textiles with specific properties are prepared by using the electrochemistry in the synthesis of conductive polymers, especially conductive fibers.

Another interesting use of the electrochemical techniques is the bleaching of cotton fibers [29] and the bleaching of finished denim fabrics [30-37]. In order to achieve the visual effect in jeans, the generation in situ of hypochlorite by electrochemical reaction has been proposed, instead of its addition.

Their application in sulfur- and vat-dyeing processes [38-61] is also interesting. In this case, dyes are reduced by means of an electrochemical reaction (instead of sodium dithionite). In this way, sulfur and vat dyeing become cleaner processes as the addition of chemical reagents is not required.

Although the electrochemical methods play an important role in the different textile processes listed above, their wider range of applications are related to color removal in wastewater treatments [62-115], in particular, in the degradation of nonbiodegradable dyes (such as reactive dyes). This kind of dyes requires additional treatments to obtain uncolored effluents. In general, the electrochemical methods are cleaner than physicochemical and membrane technologies (the current methods for color removal) because they use the electron as unique reagent and they do not produce solid residues.

The objective of this paper is to review the main applications of electrochemical techniques in textile industry (production processes and wastewater treatments). Nowadays, there are only few applications at industrial scale as most of electrochemical treatments are still being studied at laboratory scale. Therefore, it is convenient to encourage the research on new applications of these techniques because they provide some important benefits. As far as we know, 
this is the first review article dealing with the use of the electrochemical methods in the textile industry. Other authors have discussed these techniques focused on the wastewater decoloration treatments $[71-73,75,76]$, or even specifically focused on heterogeneous catalysis method [62], but the review of the different electrochemical applications in the whole textile sector has not been considered.

\section{The Electrochemistry in the Textile Production Processes}

2.1. Textile Process. The textile industry is a very important sector because textile materials are used in many different ways: wearing clothes which change every season following the new tendencies or technical fabrics (waterproof, medical textiles, etc.) which are extended to new areas of application with some different functions. Textile development normally aimed in how it can enhance the comfort to the users.

Figure 1 summarizes the textile process which starts with fibers (which can be natural, that is, silk or cotton, or synthetic such as polyester). Then the fibers preparation process is carried out, where the fibers are treated to be spuin (as carding process for wool fibers, or bleaching process for cotton fibers). The spinning process transforms the fibers into yarns, followed by the weaving of those yarns. After that, a finishing process is applied. It is based on giving color to the fabric by means of dyeing or printing processes and on other processes such us softening or bleaching denim fabrics to obtain the degraded visual effect. The dyeing process produces highly colored effluents, which have to be treated and then, they could be reused in a new dyeing process, as it is shown in Figure 2. The next step is the clothing process and finally the textile commercial product is obtained.

\subsection{Functionalization of Synthetic Textile Fibers to Obtain} "Smart Textiles". Smart textiles are those which can note external stimuli and produce a controlled effect to these stimuli. The basis to obtain these materials is on the fibers preparation, where the electrochemistry is applied to obtain functionalized synthetic fibers, such as conductive polymers [1].

Table 1 summarizes some relevant papers about the synthesis of conductive fibers. The references are classified according to the aim of the electrochemical process:

Manufacturing of the polymers. An electrochemical method is applied to obtain a stable conducing material as product. Depending on the character of the monomers, the reaction could be a polymerization (same monomer) or copolymerization (different monomers).

Grafting. This process is based on the modification of the fibers by inserting different organic compounds using an electrochemical reaction.

Superficial Treatment. A complex reaction between a metal $(\mathrm{M}+)$ and the chemical structure of the fiber takes place (this process is mainly used with metals). The first step is an approximation of the metal to the fibrous surface, and then an electrochemical reaction (mainly reduction) gives fibers with conductive properties.

As indicated, smart textiles can react to environmental stimulus or mechanical forces which produce an electrical impulse that goes through the fiber. The response to this stimulus will be different depending on its function [21]. Examples of these applications are:

(i) Clothing and home indoors, where the stimulus reaction is a change on the aesthetics of the textiles, that is color, texture, shape, and so forth.

(ii) Computer, electronic, and communication systems, where the textiles can transfer data to the body or to entertainment products.

Nowadays, these conductive polymers are used mostly as electrodes in fuel cells and batteries. Carbon fibers and nanofibers are the most common materials (references listed in Table 2).

Lopes et al. [28] compared three different anode materials: iron, conducting polymer (Polypyrrole- (Ppy- ) doped with chromium in wool textile), and boron doped diamond (BDD) electrode applied to degradation of a direct dye (Direct Red 80 ). With all of them, 99\% of dye degradation was obtained, but BDD electrode also achieved $87 \%$ of COD removal instead of $45-50 \%$ achieved with the other electrodes (namely, iron and Ppy).

The functionalization of synthetic textile fibers to obtain smart textiles is a priority research area of national and European projects calls due to its interest in the energetic sector. However, it has not been widely considered in this section because it is mainly studied from the point of view of material science. This paper is mainly focused on the textile mill production processes.

2.3. Fibers Preparation: Bleaching of Cotton Fibers. Cotton bleaching takes place after the scouring process with the aim of destroying the natural raw color of this fiber. The most common reactive to provide whiteness to cotton is hydrogen peroxide. Chong and chu [29] reported the use of electrochemical techniques to generate in situ this oxidant required for cotton bleaching by the electrolysis of oxygen in the presence of an alkaline electrolyte. This electrolyte proceeds from the scouring process. They propose the use of the electrolysis process in a combined scouring and bleaching process, and they concluded that the whiteness obtained in the combined method is comparable to that obtained with conventional methods.

2.4. Bleaching of Denim Fabrics. Although the electrochemical techniques have been applied to bleach raw fibers, their main application in bleaching field is the discoloration of indigo-denim-dyed fabrics. An important step in the processing of indigo-dyed textiles is the finishing of the garment to obtain the required visual effect (as age-worn). The removal or destruction of part of indigo requires a combination of mechanical agitation and chemical attack, mainly with oxidizing agents. 


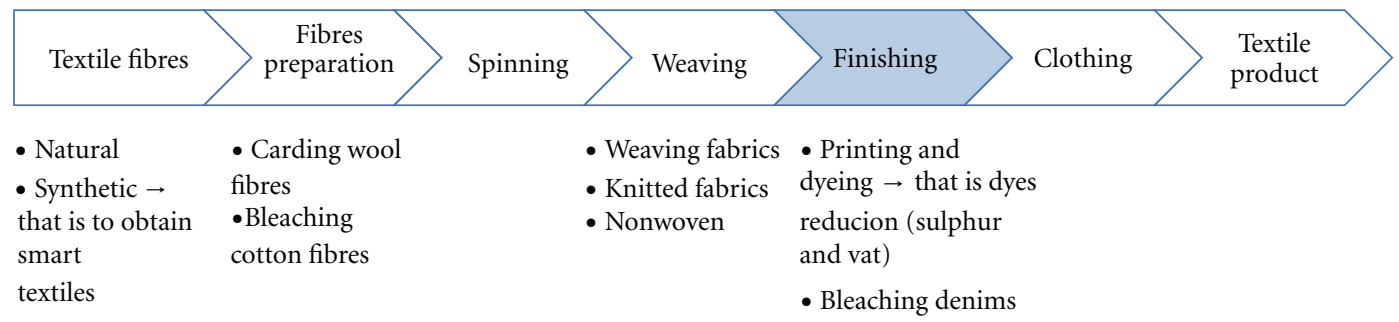

Figure 1: Textile process.

TABLE 1: Summary of methods to obtain conductive materials.

\begin{tabular}{llc}
\hline Method & Subject & Reference \\
\hline Copolymerization & Amines & {$[2-4]$} \\
Copolymerization & PSPMS and polypyrrole & {$[5]$} \\
Copolymerization & Thiophenes & {$[6-9]$} \\
Copolymerization & Polypyrrole and polyaniline in polyester textiles & {$[10]$} \\
Polymerization & Benzene + pyridine compounds & {$[11]$} \\
Polymerization & Pyrrole on polyester textiles & {$[12]$} \\
Grafting & Cotton + methyl metacrylate \\
Grafting & Rayon viscose + vinyl acetate \\
Grafting & Natural fibers \\
Grafting & Rayon viscose with different electrodes & {$[13]$} \\
Superficial treatment & General proceeding & {$[14]$} \\
Superficial treatment & Polyacrylonitril + Ni \\
Superficial treatment & Polypyrrole & {$[15]$} \\
Superficial treatment & Ion-exchanger fibers with Cu & {$[17]$} \\
\hline
\end{tabular}

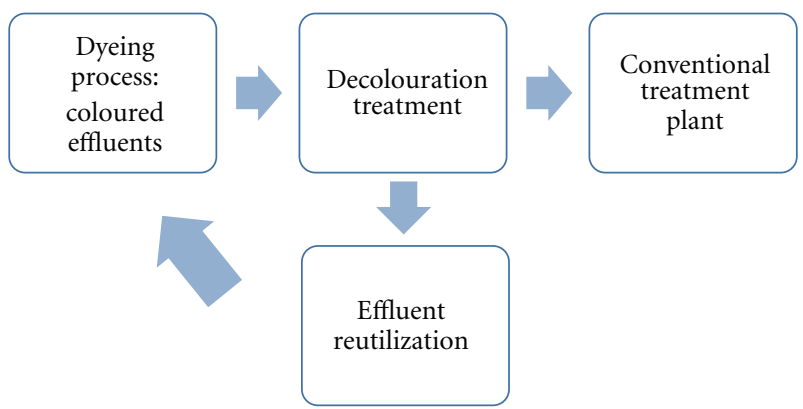

Figure 2: Dyeing effluent treatment and optional reuse.

TABLE 2: Materials and application of textiles and related conductive polymers.

\begin{tabular}{llc}
\hline Material & Application & Reference \\
\hline Carbon fibers & Fuel cells & {$[22]$} \\
Carbon fibers & Fuel cells & {$[23]$} \\
Carbon fibers & Semifuel cells & {$[24]$} \\
Carbon nanofibers & Lithium batteries & {$[25]$} \\
Carbon nanotubes & Double layer capacitors & {$[26]$} \\
Carbon fibers & Lithium batteries & {$[27]$} \\
\hline
\end{tabular}

The most useful oxidant for bleaching indigo denims is hypochlorite. The conventional method to obtain the decolorized effect of these denims is based on the addition of this chemical reagent to the dye bath, but recently the generation in situ of the hypochlorite by an electrochemical oxidation is becoming a more attractive method, because it offers several advantages with respect to the conventional method [30]:

(i) Improvement in the process control and consistency,

(ii) Lower-process costs due to the production of more regular shades, the possibility of bleaching bath regeneration and the lower amount of effluent generated.

The addition of other chemical products or its presence in the solution, such as bromide, can increase the bleaching effect because of the stronger oxidants formation (as hypobromite [31-33]) but this could affect the shade bleach [34]. The same authors in a previous study [35] noted that electrochemical method showed more intensive bleach effects than the classical one and described in their paper that the electrochemical bleaching was due to both oxidation and reduction processes.

Bechtold et al. [36] attempted to bleach denim indigo fabrics using BDD electrodes and peroxodisulfate as oxidant (coming from sodium sulfate oxidation) and the results showed that this method was not effective enough for indigo discoloration. 


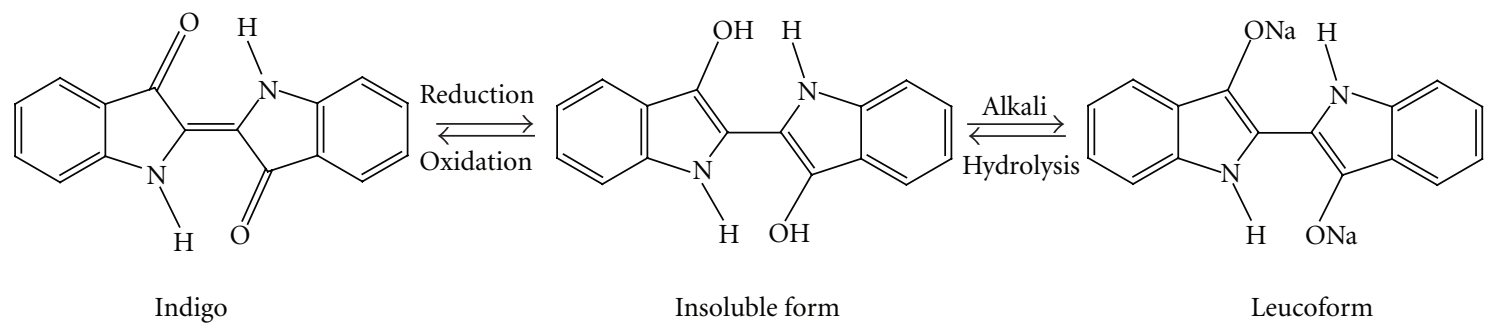

Figure 3: Reaction of indigo dye to leucoform (soluble form).

The use of photocatalysis methods [37] also showed good bleaching results in indigo carmine denims. In this case, the oxidation took place via hydroxyl radicals, and the presence of bromide and carbonate also affected the efficiency of the oxidative reaction.

2.5. Dyeing Process: Dyes Reduction. Vat dyes, especially indigo, play an important role in textile industry. This kind of dyes can be used in printing [38], but they are mostly applied in dyeing processes. They are insoluble in water and cannot dye fibers directly. They must be reduced in alkali medium to become soluble in water, as it is showed in Figure 3. When the dyes are absorbed onto the fiber, they return to their original form by a subsequent reoxidation.

Sulfur dyes also are water-insoluble dyes, containing sulfur as an integral part of the chromophore group. The alkaline-reduced form is required for the dyeing process and subsequently, when they are added to the fiber, they are oxidized to the insoluble form.

In attempt to increase the ecoefficiency of these dyeing processes, electrochemical techniques have been investigated in the reduction of such dyes, which avoids the addition of reducing agents as sodium dithionite.

Predominantly, they are used for cellulosic fabrics, mainly cotton, but there are some papers showing their availability for biodegradable fibers such as poly (lactic acid) [39], and in synthetic fibers as polyester blends [40] or nylon $6.6[41-43]$.

Sodium dithionite $\left(\mathrm{Na}_{2} \mathrm{~S}_{2} \mathrm{O}_{4}\right)$ is the most used reducing agent in the industrial dyeing process with this kind of dyes, but after its reaction, it cannot be recycled. It also produces large amounts of sodium sulfate and toxic sulfite products. For this reason, the treatment of dyeing effluents requires the addition of hydrogen peroxide [44], which also causes high costs and other additional problems (high-salt load, depletion of dissolved oxygen, nasal nuisance, toxicity of sulfide, etc.) [45]. In order to reduce these pollutants, some tests at laboratory scale pilot have been done to obtain an alternative less harmful process. There are three investigation paths based on: (a) more eco-friendly chemical reducing agents (thiourea dioxide [46], hydroxiketones [47, 48], sodium borohydride [49], etc.); (b) on physical methods [50] like ultrasound, magnetic fields or UV, but they only could be useful as accelerators of classic oxidation or reduction methods; (c) the most attractive new procedures to reduce vat and sulfur dyes are electrochemical reduction methods, because the addition of reducing agents is not required. This last method also avoids the generation of toxic products due to the reaction between the added reagents and the dye molecules. For all these reasons, electrochemical reduction processes are considered more suitable: no reagents addition is required, no byproducts are formed and no tertiary treatments are necessary to treat the final effluents. The energy is the only requirement of electrochemical methods.

The electrochemical reduction of textile dyes can be divided into direct and indirect reduction. Schrott [51] indicated that sulfur dyes can be reduced directly, but in the case of vat dyes and indigo, the reaction probably occurs by indirect reduction because of their low solubility in water (consequently they have low contact to the surface of the cathode).

The electrochemical reduction processes studied are:

(i) Indirect reduction, where sometimes iron complexes act as mediators $[52,53]$.

(ii) Direct reduction via radical, for sulfur dyes (using a multicathode cell made of stainless steel electrodes) [54] or indigo dye (using a nickel cathode electrode) [55]. Both of them have effectiveness between 70$90 \%$. A radical anion, formed by a comproportionation reaction between the insoluble dye and the leucoform is the responsible of the electrochemical reduction [56].

(iii) Direct reduction on graphite electrodes [57], which are extensively used because of their high surface area [56].

(iv) Electrolytic hydrogenation, which is based on the hydrogen formation, produced in situ by water electrolysis. The hydrogen reacts with dyes adsorbed at the electrode surface. Different electrodes and catalysts have been studied [58].

According to Roessler and Jin [56], the direct electrochemical reduction of vat dyes by graphite granules is the most attractive method because of its stability, cost, and availability. Roessler and Crettenand [45] studied the kinetic rates of some vat dyes and they noted that graphite electrodes were suitable for all them. Also, they concluded that the reduction rate decreased with the increase of dyes lipophility because of aggregates formation.

To improve these methods in order to be applied at industrial scale, some investigations have been carried out, 


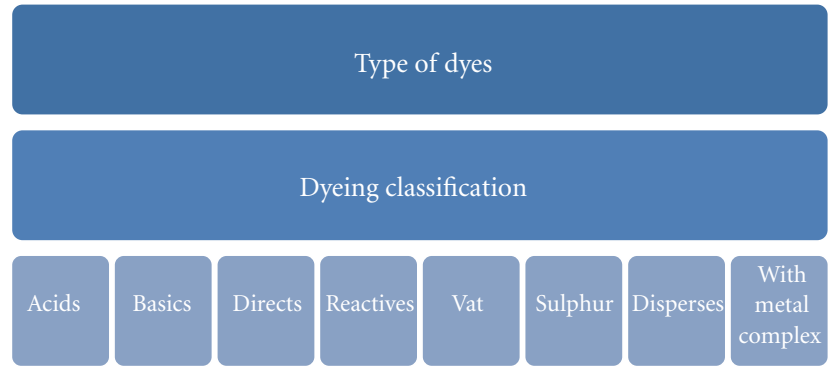

Figure 4: Dyes classification.

that is, several reviews $[59,60]$ are available on functionalizing the surface of carbon electrodes to obtain higher reduction rates with the same color intensity and washing fastness than traditional methods [61]. Furthermore the possibility of reusing these electrodes is a subject of the study.

The reuse of the reducing agent (by regeneration in a cathodic reduction) and also the dyeing bath in the indirect reduction electrochemical method, using a mediator, has been studied [53] but the final color was poorer than the one obtained by the traditional method with sodium dithionite.

Taking into account all these studies, we can conclude that the use of electrochemical techniques constitute a promising field for the different steps of textile process, but their application to the dyeing of vat and sulfur dyes is specially interesting to avoid the use of reducing reagents.

\section{Wastewater Color Removal}

3.1. Textile Wastewater Concern. The textile industry produces large volumes of wastewater in its dyeing and finishing processes. These effluents have as common characteristic their high coloration. Colorants, the additive substances that cause a variation in color, can be divided in dyes or pigments. Pigments in general are insoluble substances which have not the chemical affinity to the substrate to be colored; otherwise, dyes are generally soluble (or partially soluble) organic compounds, which interact with the fiber or leather imparting color [62]. Figure 4 summarizes the different textile dyes according to their dyeing behavior.

Most of electrochemical discoloration studies are focused on reactive dyes. They represent about $20-30 \%$ of the total market [63], because of their solidity and brilliant color. Their structure consists on a reactive group (which reacts with the fiber), and a chromophore group (which gives the color). The most used chromophore group is the "azo" ( $\mathrm{R}-$ $\mathrm{N}=\mathrm{N}-\mathrm{R}^{\prime}$ ), followed by the anthraquinone group [64]. Azo group constitute, more than half of worldwide production [65], approximately 65\% [66-68]. Moreover, this kind of dyes produces toxic aromatic products in their degradation.

The dyeing reaction, when a triazine is the reactive group, occurs by a nucleophilic displacement of the chlorine atom from the reactive group to the hydroxyl group from the cellulose in alkaline medium, as it is shown below [69].
Reaction 2:

$$
\text { dye- } \mathrm{Cl}+\mathrm{HO} \text {-cellulose } \longrightarrow \text { dye-O-cellulose }+\mathrm{HCl}
$$

The competitive reaction between dye and water produces dyes hydrolysis (reaction 3). The hydrolyzed dyes cannot react with the fiber, being the element responsible for the colored effluents.

Reaction 3:

$$
\text { dye- } \mathrm{Cl}+\mathrm{H}_{2} \mathrm{O} \longrightarrow \text { dye- } \mathrm{OH}+\mathrm{HCl}
$$

The high consumption of reactive dyes, mainly in the cotton industry, increases this environmental and aesthetic problem, due to their low degree of exhaustion, and their presence both in dyeing and soaping effluents.

Other chemical products present in the dyeing process (such as $\mathrm{Na}_{2} \mathrm{CO}_{3}$ used to set the $\mathrm{pH}$ in the dyeing bath which has an important role in dyes fixation to the fiber and color fastness; or $\mathrm{NaCl}$ added to transfer the dyestuff to the fabric) can influence the electrochemistry process as they can scavenge ${ }^{\bullet} \mathrm{OH}$ and $\mathrm{h}_{\nu \mathrm{b}}{ }^{+}$) [70].

Several methods are used for the removal of organic dyes from wastewaters. Most of dyes are only partially removed under aerobic conditions in conventional biological treatments. As biological treatment is insufficient to remove color and to accomplish with current regulations, the application of specific treatments is required. The effluent color regulations are very variable depending on the Country. In $\mathrm{UK}$, the color value is calculated from some absorbance measurements. State and USA federal agencies have been requiring low effluent color limits $(<200$ units of the American Dye Manufacturers Institute, ADMI). While the implementation of the Cluster Rules did not place regulatory limits on color, the U.S. EPA left the option open for regulatory authorities to establish limits on color based on the individual circumstances of each holder and watershed. In Spain, the colored effluents are allowed to be discharged if no color is observed after a $1 / 20$ dilution (Real Decreto $849 / 1986$ ), although each regional authority can restrict this value.

The different techniques to achieve effective color removal, according to Martínez-Huitle and Brillas [71], are schematically indicated in Figure 5.

Some electrochemical color removal methods have been applied to industrial effluents. The current physico-chemical methods, based on the separation of dyes from the effluents, produce a residue which requires an additional treatment to be destroyed. Also, the absorbent materials (such as active carbon, silica gel, or alumina) require their regeneration after several treatments [72], and the filtration and membranes methods need cleaning treatments. Chemical oxidation methods are rather expensive and involve some operational difficulties $[73,74]$. Biological treatments are a simple method but supply inefficient results in discoloration because dyes have aromatic rings in their large molecules that provide them chemical stability and resistance to the microbiological attack [75]. Enzymatic decomposition requires 


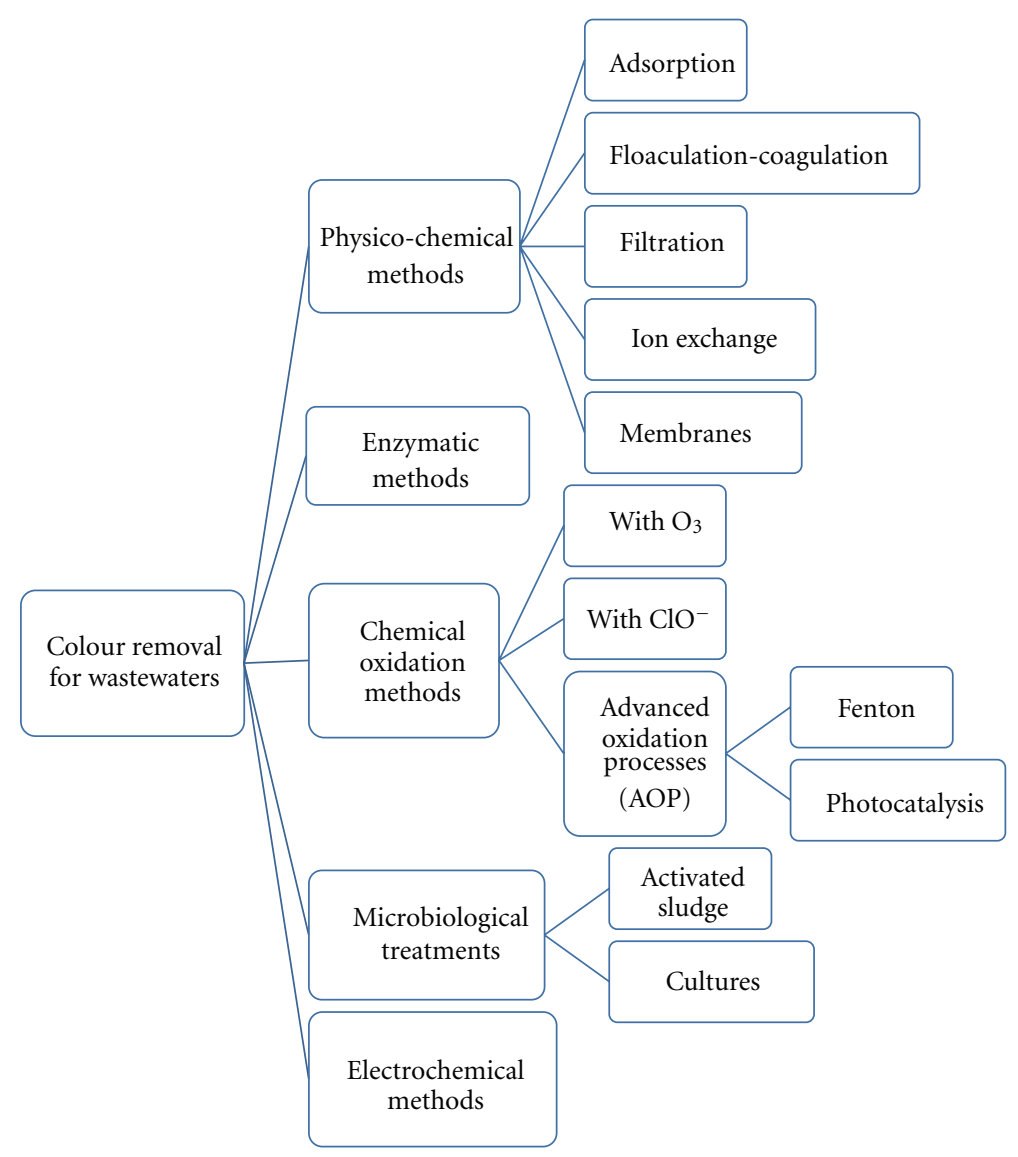

FIgURe 5: Methods for textile wastewater color removal.

further investigation in order to know which enzymatic process takes place [76]; moreover, temperature and pressure have to be controlled to avoid enzymes denaturalization.

For these reasons, the electrochemical methods are nowadays the subject of a wide range of investigations at laboratory and pilot-plant scale. The advantage of these electrochemical techniques is that electron is a clean reagent. They also have good versatility and high-energy efficiency. They are easy for automation and safety because it is possible to operate at smooth conditions [77]. Figure 6 represents the main types of electrochemical methods applied to wastewater treatment, briefly described below.

3.2. Electrocoagulation Methods. Electrocoagulation systems provide electrochemical aggregation of heavy metals, organic and inorganic pollutants, to produce a coagulated residue to be separated or removed from water.

This technique is an indirect electrochemical method which produces coagulant agents $\left(\mathrm{Fe}^{3+}\right.$ or $\left.\mathrm{Al}^{3+}\right)$ from the electrode material ( $\mathrm{Fe}$ or $\mathrm{Al}$ ) in hydroxide medium. These species, that is, $\mathrm{Fe}(\mathrm{OH})_{3}$, can remove dissolved dyes by precipitation or by flotation [78, 79]. These complexed compounds are attached to the bubbles of $\mathrm{H}_{2 \text { (gas) }}$ evolved at the cathode and transported to the top of solution. The inconvenient of the electrocoagualtion in comparison to the other electrochemical methods is that it produces secondary residues (the complex formed with pollutant and hydroxide) which implies the use of tertiary treatments.

3.3. Electrochemical Reduction Methods. The electrochemical reduction method has been discussed in a restricted number of papers because its yield in pollutants degradation is poor in comparison to direct and indirect electrooxidation methods [71]. Bechtold et al. [80], consider that this method is particularly suitable for the treatment of highly colored wastewaters such as the residual pad-batch dyeing bath with reactive dyes. The dye reduction takes place producing hydrazine (in the partial reduction) and its total reduction generates amino compounds (scheme in Figure 7). They remark the importance of a divided cell in the case of dye baths containing chlorides; this division is important to avoid the formation of chlorine and chlorinated products.

In the same way, Vanerkova et al. [81] proposed a reduction mechanism for the azo dyes degradation with platinated titanium electrodes $(\mathrm{Pt} / \mathrm{Ti})$ in the presence of $\mathrm{NaCl}$. In this study, the action of hypochlorite generated by oxidation of chloride is also discussed Zanoni et al. [69] studied the hydrolysis under reduction process of two anthraquinone reactive dyes. They demonstrate that the acidic medium provides the best conditions, and that the presence of borate in the solution modifies the reduction process. 


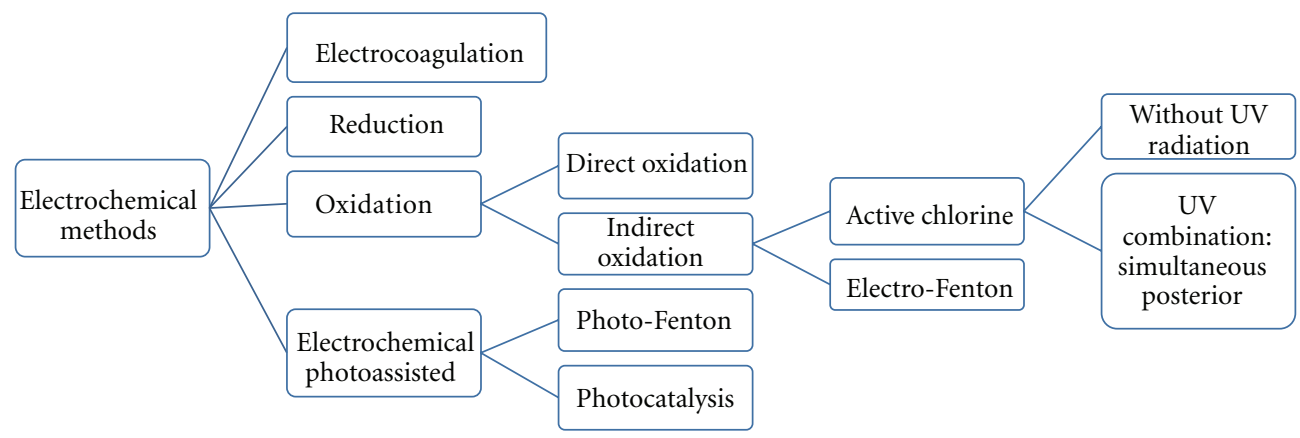

FIGURE 6: Electrochemical methods.

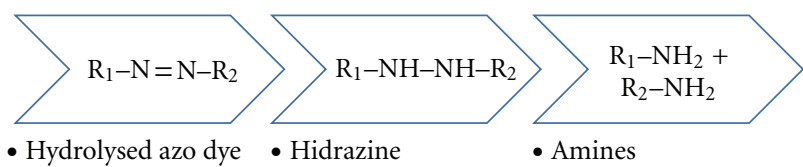

FIgURE 7: Reduction process for azo dyes.

3.4. Electrochemical Oxidation Methods. The electrochemical oxidation is a process based on pollutants removal by direct anodic oxidation (which generally produces poor decontamination) or by chemical reaction with electrogenerated species (hydroxyl radical $\mathrm{M}\left[\mathrm{OH}^{\bullet}\right]$ or metal oxide [MO], as it is showed in the follow reaction) [71]. The reactive dyes degradation can be partial or total, according to the following mechanism:

Reaction:

$$
\begin{gathered}
\mathrm{H}_{2} \mathrm{O}+\mathrm{M} \longrightarrow \mathrm{M}\left[\mathrm{OH}^{\bullet}\right]+\mathrm{H}^{+}+\mathrm{e}^{-} \\
\mathrm{R}+\mathrm{M}\left[\mathrm{OH}^{\bullet}\right] \longrightarrow \mathrm{M}+\mathrm{RO}+\mathrm{H}^{+}+\mathrm{e}^{-}
\end{gathered}
$$

Many studies have shown that the total mineralization is possible with high efficiencies depending on the anode material $\left(\mathrm{SnO}_{2}[82,83], \mathrm{PbO}_{2}\right.$ [84-86], BDD [87-92], $\mathrm{Ti} / \mathrm{SnO}_{2} / \mathrm{SbO}_{x} / \mathrm{RuO}_{2}$, and $\mathrm{Ti} / \mathrm{TiO}_{2}$ [63]). However, the dye solution is not decolorized effectively using both glassy and reticulated vitreous carbon electrodes [63]. The borondoped diamond (BDD) thin-film electrodes have physical characteristics as an inert surface with low-adsorption properties, good corrosion stability, and a wide potential window in aqueous medium [93]. In spite of its high cost, the BDD electrode has much greater $\mathrm{O}_{2}$-thovervoltage than de conventional anodes ( $\mathrm{Pt}, \mathrm{PbO}_{2}$, etc.). Consequently, that produce generates more amount of $\left[\mathrm{OH}^{\bullet}\right]$ which implies a faster oxidation of the pollutants [94].

In the same way, Martínez-Huitle and Brillas [71] compared different kinds of electrodes in two types of wastewaters (chloride-free dye wastewaters and effluents which contain chloride). They supported that most of the anodes tested could destroy the chromophore group $(-\mathrm{N}=\mathrm{N}-)$ producing its discoloration efficiently, and when chloride was present, the destruction of dyes was accelerated by active chlorine species produced.
3.5. Indirect Oxidation Methods. The indirect electrooxidation occurs when strong oxidants are generated in situ during the electrolysis and react with the organic pollutants such as dyestuffs, producing its total or partial degradation.

Mainly two methods one used:

(i) The first one is the electro-oxidation with active chlorine $[95,96]$ which is the major oxidizing agent. In this case, free-chlorine gaseous and/or the generated chlorine-oxygen species such as hypochlorous acid $(\mathrm{HClO})$ or hypochlorite ions $\left(\mathrm{ClO}^{-}\right)$depending on the $\mathrm{pH}$, oxidize the organic matter present in the effluents, according to the following reactions:

Reactions:

$$
\begin{gathered}
2 \mathrm{Cl}^{-} \longrightarrow \mathrm{Cl}_{2(\mathrm{aq})}+2 \mathrm{e}^{-} \\
\mathrm{Cl}_{2(\mathrm{aq})}+\mathrm{H}_{2} \mathrm{O} \longrightarrow \mathrm{ClO}^{-}+\mathrm{Cl}^{-}+\mathrm{H}^{+} \\
\text {Dye }+\mathrm{ClO}^{-} \longrightarrow \text { dye intermediates } \longrightarrow \mathrm{CO}_{2}+\mathrm{H}_{2} \mathrm{O}+\mathrm{Cl}^{-}
\end{gathered}
$$

(ii) The second one is the electro-Fenton process [97], where organics degradation occurs by hydroxyl radicals $\left(\mathrm{OH}^{\bullet}\right)$ formed from Fenton's reaction between catalytic $\mathrm{Fe}^{2+}$ and $\mathrm{H}_{2} \mathrm{O}_{2}$, this hydrogen peroxide is also electrogenerated from $\mathrm{O}_{2}$ reduction.

Reactions:

$$
\begin{gathered}
\mathrm{O}_{2(\mathrm{~g})}+2 \mathrm{H}^{+}+2 \mathrm{e}^{-} \longrightarrow \mathrm{H}_{2} \mathrm{O}_{2} \\
\mathrm{O}_{2(\mathrm{~g})}+\mathrm{Fe}^{2+} \longrightarrow \mathrm{Fe}^{3+}+\mathrm{OH}^{\bullet}+\mathrm{OH}^{-}
\end{gathered}
$$

Thus, $\mathrm{Fe}^{2+}$ is continuously regenerated from the reduction of $\mathrm{Fe}^{3+}$ :

$$
\mathrm{Fe}^{3+}+\mathrm{e}^{-} \longrightarrow \mathrm{Fe}^{2+}
$$

This technique has an important inconvenience: a strong acidic medium is required. As the reactive dyeing process is carried out in basic medium (generally $\mathrm{pH}>10$ ), 
a high amount of acid has to be added before the treatment. Subsequently, the treated effluent must be neutralized to be discharged. Consequently, the whole process produces a high increase of the wastewater salinity.

As some industrial wastewaters contain large amounts of chloride, the first approach is more suitable to treat this kind of effluents, because the addition of any chemical product is not required whereas in second case, Fenton reagent is needed. In contrast, the combination of electrochemistry and chloride can produce haloforms such as chloroform, although it is not an inconvenient if the treated water is degraded lately in a biological plant to accomplish its mineralization. In fact, it has been verified that the concentration of haloforms is very low and they do not show any toxic effect on the plant microorganisms [98]. Otherwise it is possible to remove the haloform generated by placing a UV lamp in the electrochemical cell where the reaction takes place [99], or by adding $\mathrm{H}_{2} \mathrm{O}_{2}$ into the wastewater before the reaction had started. The first approach was studied by López-Grimau and Gutiérrez [100] and it was found to improve the kinetic rates of electrochemical degradation of some reactive azo dyes with $\mathrm{Ti} / \mathrm{PtO}_{x}$ electrodes. The electrochemistry method using chlorine has been noted to be effective in other kind of dyes, such as acid dyes [101] or disperse dyes [102], and combined with photoelectrochemistry has also obtained good results for phtalocyanine dyes degradation [103], but in this case, the metal ions liberated (as copper) have to be removed.

3.6. Photo-Assisted Methods. The photoassisted electrochemical methods are based on the exposure of the effluent to a UV light source during the electrochemical treatment. In these procedures, the intensity and the wavelength of the incident light plays an important role on the mineralization rate.

The most studied photoassisted method is the photoFenton [105], which consists in the simultaneous use of UV light and $\mathrm{H}_{2} \mathrm{O}_{2}$ (electrogenerated in situ with the presence of $\mathrm{Fe}^{2+}$ ); followed by the heterogeneous $\mathrm{TiO}_{2}$ photocatalysis method [106]. Although several photocatalysts $\left(\mathrm{TiO}_{2}, \mathrm{WO}_{3}\right.$, $\left.\mathrm{SnO}_{2}, \mathrm{ZnO}, \mathrm{CdS} . ..\right)$ act via hydroxyl radical and generate powerful oxidants, the $\mathrm{TiO}_{2}$ under UV radiation has been the preferred catalyst, due to its low cost, nontoxicity, water insolubility and wide band gap, which consequently implies a good stability and prevents photocorrosion [62, 70, 107112]).

Moreover, Carneiro et al. [70] noted that the use of photocatalysis with $\mathrm{Ti} / \mathrm{TiO}_{2}$ electrodes achieves efficiently discoloration with both electrolytes, $\mathrm{NaCl}$ and $\mathrm{Na}_{2} \mathrm{SO}_{4}$. Their efficiency depend on the $\mathrm{pH}$.

Xie and $\mathrm{Li}$ [113] reported the coupling of electroFenton with electrocatalysis for the removal of an azo dye. With respect to other electro-oxidation and photoassisted methods, their results showed a better removal of the dye in the coupled system. The major disadvantage of these methods was the excessive energy cost of the artificial UV light used. However, this problem is easy to solve by using sunlight $[114,115]$ as inexpensive energy source although it had less catalytic power.
Additionally, the combination between the indirect oxidation methods with the UV irradiation has been the subject of recent investigations. According to Sala [116], the energy consumption is around $5.7 \mathrm{~kW} / \mathrm{h} / \mathrm{m}^{3}$ to achieve discoloration higher than $90 \%$ when the photoelectrochemical treatment is applied to real industrial effluents by means of a semi-industrial pilot. The discoloration process follows a pseudo-first-order kinetic in the case of monochromies and a second order kinetics in the case of trichromie, evaluated at the maximum absorbance wavelength of the trichromie, which corresponds mainly to the contribution of two dyes (due to the low absorbance of the third dye at the selected wavelength).

By another hand, the actual policies concerning water and energy consumption conduce to recycling and reuse treatments. In this sense, recent studies [104] demonstrate the possibility of reusing these discolored effluents for new dyeing processes. The reuse of $70 \%$ of discolored dyebaths, after electrochemical treatment assisted by UV irradiation, provides in most of cases, low color differences $\left(\mathrm{DE}_{\mathrm{CMC}(2: 1)} \leq 1\right)$ with respect to the original dyeing with decalcified tap water. This value increases from the first step until the 4th or 5th cycle of electrochemical treatment and reuse, where $\operatorname{DE}_{\mathrm{CMC}(2: 1)}$ become constant. In some cases, when the bath is reused, an extra amount of dye must be added to obtain the required color.

Numerous studies can be found about the electrochemical discoloration of textile wastewater, but some authors have advanced a further step: in the case of indirect oxidation with active chlorine, the conditions for the effluents reutilization have also been optimized [99, 100, 104]. In this sense, Gutierrez-Bouzan et al. in a recent patent (ES201131159) claimed a process "UVEC Cell" for the discoloration and reuse of reactive dyes effluents in a new dyeing process. Both prototype and procedure are patented, based on an electrochemical cell combined with UV source for the treatment and reuse of textile effluents saving more than $60 \%$ water and electrolyte.

\section{Conclusions}

The electrochemical techniques have been proved to be efficient in different oxidation or reduction steps of the textile processes such as: bleaching denim fabrics or reduction of sulfur and vat dyes, where their applications are available in both natural and synthetic fibers. They constitute a less harmful alternative than the traditional processes. They also have been studied in new textile fields, such as in the production of conductive polymers used as fibers which are applied in smart textiles to produce fabrics with new functions.

In addition, the electrochemical treatments have been extensively applied to the decontamination of wastewaters from the textile processes. They have been mainly used in the removal of residual reactive dyes, but also in the discoloration of acid and disperse dyes effluents. Taking into account the considerable amount of salt contained in the reactive dyes residual dyebath, the best method for the treatment of these 
effluents is the indirect oxidation with chlorine, because of the following:

(i) The degradation takes place in the same bath.

(ii) The addition of chemical reagents is not required (the residual salts act as electrolyte).

(iii) The modification of the $\mathrm{pH}$ is not necessary.

(iv) No solid waste is generated.

(v) The reuse of the treated effluent for new dyeing is possible, which implies a saving of $70 \%$ water and $60 \%$ salt.

The combination with UV and solar irradiation improved the discoloration kinetic rates in different electrochemical techniques, and in some cases, the UV light exposure also removes the undesirable compounds (such as chloroform) or avoids their generation according to the patent ES201131159 (“UVEC Cell").

The possibility of reusing dyeing effluents treated by electrochemical methods is particularly interesting and it implies an important saving of water and salt. This kind of studies are especially important in Mediterranean countries, where the river flow rates are low and their salinity is nowadays an increasing environmental problem.

The bases of electrochemistry are simple but, as showed in this review, it is possible to find the application of these techniques in a wide range of textile processes.

\section{Acknowledgment}

The authors acknowledge the financial support of the Catalan Agency for the Innovation ACC10-CIDEM/COPCA (Project J-04015).

\section{References}

[1] S. Baurley, "Interactive and experiential design in smart textile products and applications," Personal and Ubiquitous Computing, vol. 8, no. 3-4, pp. 274-281, 2004.

[2] F. Cases, F. Huerta, R. Lapuente, C. Quijada, E. Morallón, and J. L. Vázquez, "Conducting films obtained by electrooxidation of $p$-aminodiphenylamine (ADPA) in the presence of aniline in buffer aqueous solution at $\mathrm{pH} 5$," Journal of Electroanalytical Chemistry, vol. 529, no. 1, pp. 59-65, 2002.

[3] S. Beaupré, J. Dumas, and M. Leclerc, "Toward the development of new textile/plastic electrochromic cells using triphenylamine-based copolymers," Chemistry of Materials, vol. 18, no. 17, pp. 4011-4018, 2006.

[4] M. A. Cotarelo, F. Huerta, C. Quijada, F. Cases, and J. L. Vázquez, "The electrochemical co-polymerization of paminodiphenylamine and aniline: effect of $\mathrm{pH}$," Synthetic Metals, vol. 148, no. 1, pp. 81-85, 2005.

[5] Y. H. Park, H. C. Shin, Y. Lee, Y. Son, and D. H. Baik, "Electrochemical preparation of polypyrrole copolymer films from PSPMS precursor," Macromolecules, vol. 32, no. 14, pp. 4615-4618, 1999.

[6] J. Tarábek, E. Jähne, P. Rapta, D. Ferse, H. J. Adler, and L. Dunsch, "New acetophenone-functionalized thiophene monomer for conducting films on electrodes in chemical ion-sensorics: the synthesis and spectroelectrochemical study," Russian Journal of Electrochemistry, vol. 42, no. 11, pp. 1169-1176, 2006.

[7] S. Tanaka, M. A. Sato, and K. Kaeriyama, "Electrochemical polymerization of thiophenes containing a methoxy group," Polymer communications Guildford, vol. 26, no. 10, pp. 303306, 1985.

[8] K. Kaeriyama, M. Sato, and S. Tanaka, "Electrochemical preparation of conducting polyalkylthiophene films," Synthetic Metals, vol. 18, no. 1-3, pp. 233-236, 1987.

[9] M. A. Sato, S. Tanaka, and K. Kaeriyama, "Soluble conducting polymers by electrochemical polymerization of thiophenes having long alkyl substituents," Synthetic Metals, vol. 18, no. 1-3, pp. 229-232, 1987.

[10] J. Molina, A. I. del Río, J. Bonastre, and F. Cases, "Electrochemical polymerisation of aniline on conducting textiles of polyester covered with polypyrrole/AQSA," European Polymer Journal, vol. 45, no. 4, pp. 1302-1315, 2009.

[11] S. Tanaka, M. A. Sato, and K. Kaeriyama, "Electrochemical polymerization of dithienylbenzene and dithienylpyridine," Journal of Macromolecular Science, vol. 24, no. 7, pp. 749-761, 1987.

[12] J. Molina, A. I. del Río, J. Bonastre, and F. Cases, "Chemical and electrochemical polymerisation of pyrrole on polyester textiles in presence of phosphotungstic acid," European Polymer Journal, vol. 44, no. 7, pp. 2087-2098, 2008.

[13] M. L. Dupraz and J. Rouger, "Study of the electrochemical grafting of methyl methacrylate on to cellulose. II. Study of the copolymer formed by cotton linters and polymethyl methacrylate," Cellulose Chemistry and Technology, vol. 7, pp. 63-76, 1973.

[14] T. Skwarsky, T. Mikolajczyk, and A. Krasinka, "Modification of viscose rayon fibers by electrochemical grafting of vinyl acetate," Polimery, vol. 13, pp. 301-304, 1968.

[15] S. N. Bhadani, S. K. Sen Gupta, and M. K. Gupta, "Electrically conducting natural fibres," Indian Journal of Fibre \& Textile Research, no. 18, pp. 46-47, 1993.

[16] T. Skwarsky, T. Mikolajczyk, and T. A. Krasinka, "Effect of electrode type on electrochemical grafting of methyl methacrylate on viscose rayon fibers," Polimery, vol. 13, pp. 407-410, 1968.

[17] S. Gimpel, U. Möhring, H. Müller, A. Neudeck, and W. Scheibner, "Textile-based electronic substrate technology," Journal of Industrial Textiles, vol. 33, no. 3, pp. 179-189, 2004.

[18] D. Akbarov, B. Baymuratov, P. Westbroek, R. Akbarov, K. Declerck, and P. Kiekens, "Development of electroconductive polyacrylonitrile fibers through chemical metallization and galvanisation," Journal of Applied Electrochemistry, vol. 36, no. 4, pp. 411-418, 2006.

[19] M. Watanabe, "Preparation of polypyrrole film with wellordered corrugation," Synthetic Metals, vol. 156, no. 7-8, pp. 597-601, 2006.

[20] G. M. Mubarakshin, B. M. Vrevskii, and L. A. Vol'f, "Preparation of fibrous electron-ion exchangers by an electrochemical method," Journal of Applied Chemistry of the USSR, vol. 59, no. 6, pp. 1122-1125, 1986.

[21] S. L. Baurley, "Smart textiles for future intelligent consumer products," in Proceedings of the IEEE Eurowearable, pp. 73-75, Birmingham, UK, September 2003.

[22] J. H. Lin, W. H. Chen, S. H. Su, Y. K. Liao, and T. H. Ko, "Carbon film coating on gas diffusion layer for proton exchange membrane fuel cells," Journal of Power Sources, vol. 184, no. 1, pp. 38-43, 2008.

[23] R. F. Louh, A. C. C. Chang, V. Chen, and D. Wong, "Design of electrophoretically deposited microporous layer/catalysts 
layer composite structure for power generation of fuel cells," International Journal of Hydrogen Energy, vol. 33, no. 19, pp. 5199-5204, 2008.

[24] R. R. Bessette, M. G. Medeiros, C. J. Patrissi, C. M. Deschenes, and C. N. LaFratta, "Development and characterization of a novel carbon fiber based cathode for semi-fuel cell applications," Journal of Power Sources, vol. 96, no. 1, pp. 240244, 2001.

[25] L. Ji and X. Zhang, "Generation of activated carbon nanofibers from electrospun polyacrylonitrile-zinc chloride composites for use as anodes in lithium-ion batteries," Electrochemistry Communications, vol. 11, no. 3, pp. 684-687, 2009.

[26] C. W. Huang, C. M. Chuang, J. M. Ting, and H. Teng, "Significantly enhanced charge conduction in electric double layer capacitors using carbon nanotube-grafted activated carbon electrodes," Journal of Power Sources, vol. 183, no. 1, pp. 406-410, 2008.

[27] J. F. Snyder, E. L. Wong, and C. W. Hubbard, "Evaluation of commercially available carbon fibers, fabrics, and papers for potential use in multifunctional energy storage applications," Journal of the Electrochemical Society, vol. 156, no. 3, pp. A215-A224, 2009.

[28] A. Lopes, S. Martins, A. Moraö, M. Magrinho, and I. Gonçalves, "Degradation of a textile dye C.I. Direct Red 80 by electrochemical process," Portugaliae Electrochimica Acta, vol. 22, pp. 279-294, 2004.

[29] C. L. Chong and P. M. Chu, "Bleaching cotton based on electrolytic production of hydrogen peroxide," American Dyestuff Reporter, vol. 87, no. 4, pp. 13-19, 1998.

[30] T. Bechtold, A. Turcanu, R. Campese, P. Maier, and W. Schrott, "On-site formation of hypochlorite for indigo oxidation-scale-up and full scale operation of an electrolyser for denim bleach processes," Journal of Applied Electrochemistry, vol. 36, no. 3, pp. 287-293, 2006.

[31] Y. Amano and Y. Y. Tanaka, "Treating agent for bleach processing," Japanese Patent: Application number "JP1988000226387", 1990.

[32] J. I. Friday, "Method for altering fabrics or garments to discharge dyed colors or indigo denim to create finishes," US5310409, 1994.

[33] Puttaswamy, D. S. Mahadevappa, and N. M. M. Gowda, "Kinetics and mechanism of oxidation of indigo carmine by hypohalites," International Journal of Chemical Kinetics, vol. 23, no. 1, pp. 27-35, 1991.

[34] T. Bechtold, P. Maier, and W. Schrott, "Bleaching of indigodyed denim fabric by electrochemical formation of hypohalogenites in situ," Coloration Technology, vol. 121, no. 2, pp. 64-68, 2005.

[35] R. Maier, W. Schrott, T. Bechtold, and R. Campese, "Electrochemical bleaching in the finishing of jeans," Melliand Textilberichte, vol. 85, no. 11-12, pp. 880-884, 2004.

[36] T. Bechtold, A. Turcanu, and W. Schrott, "Electrochemical decolourisation of dispersed indigo on boron-doped diamond anodes," Diamond and Related Materials, vol. 15, no. 10, pp. 1513-1519, 2006.

[37] H. Liao, D. Stenman, and M. Jonsson, "Study of Indigo carmine as radical probe in photocatalysis," Journal of Photochemistry and Photobiology A, vol. 202, no. 2-3, pp. 8691, 2009.

[38] M. D. Teli, P. Rohera, J. Sheikh, and R. Singhal, "Use of Amaranthus (Rajgeera) starch vis-à-vis wheat starch in printing of vat dyes," Carbohydrate Polymers, vol. 76, no. 3, pp. $460-463,2009$.
[39] K. Sawada and M. Ueda, "Optimization of dyeing poly(lactic acid) fibers with vat dyes," Dyes and Pigments, vol. 74, no. 1, pp. 81-84, 2007.

[40] Y. C. Chao, Y. L. Chung, C. C. Lai, S. K. Liao, and J. C. Chin, "Dyeing of cotton-polyester blends with anthraquinonoid vat dyes," Dyes and Pigments, vol. 40, no. 1, pp. 59-71, 1999.

[41] S. M. Burkinshaw, S. N. Chevli, and D. J. Marfell, "The dyeing of nylon 6,6 with sulphur dyes," Dyes and Pigments, vol. 45, no. 1, pp. 65-74, 2000.

[42] S. M. Burkinshaw, K. Lagonika, and D. J. Marfell, "Sulphur dyes on nylon 6,6-part 2: the effects of reductant, oxidant and wash-off," Dyes and Pigments, vol. 58, no. 2, pp. 157-170, 2003.

[43] S. M. Burkinshaw and K. Lagonika, "Sulphur dyes on nylon 6,6. Part 3. Preliminary studies of the nature of dye-fibre interaction," Dyes and Pigments, vol. 69, no. 3, pp. 185-191, 2006.

[44] M. Božič and V. Kokol, "Ecological alternatives to the reduction and oxidation processes in dyeing with vat and sulphur dyes," Dyes and Pigments, vol. 76, no. 2, pp. 299-309, 2008.

[45] A. Roessler and D. Crettenand, "Direct electrochemical reduction of vat dyes in a fixed bed of graphite granules," Dyes and Pigments, vol. 63, no. 1, pp. 29-37, 2004.

[46] M. Weiss, "Thiourea dioxide: a safe alternative to hydrosulfite reduction," American Dyestuff Reporter, vol. 67, no. 8, pp. 3538, 1978

[47] E. Marte, "Dyeing with sulphur, indigo and vat dyes using the new RD process. Hydroxyacetone makes it possible," Text Praxis International, vol. 44, p. 737, 1989.

[48] U. Baumgarte, "Developments in vat dyes and in their application 1974-1986," Review of Progress in Coloration, vol. 17, pp. 29-38, 1987.

[49] N. Meksi, M. Kechida, and F. Mhenni, "Cotton dyeing by indigo with the borohydride process: effect of some experimental conditions on indigo reduction and dyeing quality," Chemical Engineering Journal, vol. 131, no. 1-3, pp. 187-193, 2007.

[50] D. Thetford and A. P. Chorlton, "Investigation of vat dyes as potential high performance pigments," Dyes and Pigments, vol. 61, no. 1, pp. 49-62, 2004.

[51] W. Schrott, "Electrochemical dyeing," Textile Asia, vol. 35, no. 2, pp. 45-47, 2004.

[52] B. Thomas and T. Aurora, "Iron-complexes of bis(2hydroxyethyl)-amino-compounds as mediators for the indirect reduction of dispersed vat dyes - cyclic voltammetry and spectroelectrochemical experiments," Journal of Electroanalytical Chemistry, vol. 591, no. 1, pp. 118-126, 2006.

[53] M. A. Kulandainathan, A. Muthukumaran, K. Patil, and R. B. Chavan, "Potentiostatic studies on indirect electrochemical reduction of vat dyes," Dyes and Pigments, vol. 73, no. 1, pp. 47-54, 2007.

[54] T. Bechtold, E. Burtscher, and A. Turcanu, "Direct cathodic reduction of Leuco Sulfur Black 1 and Sulfur Black 1," Journal of Applied Electrochemistry, vol. 28, no. 11, pp. 1243-1250, 1998.

[55] A. Roessler, D. Crettenand, O. Dossenbach, W. Marte, and P. Rys, "Direct electrochemical reduction of indigo," Electrochimica Acta, vol. 47, no. 12, pp. 1989-1995, 2002.

[56] A. Roessler and X. Jin, "State of the art technologies and new electrochemical methods for the reduction of vat dyes," Dyes and Pigments, vol. 59, no. 3, pp. 223-235, 2003.

[57] A. Roessler, D. Crettenand, O. Dossenbach, and P. Rys, "Electrochemical reduction of indigo in fixed and fluidized beds 
of graphite granules," Journal of Applied Electrochemistry, vol. 33, no. 10, pp. 901-908, 2003.

[58] A. Roessler, O. Dossenbach, W. Marte, and P. Rys, "Electrocatalytic hydrogenation of vat dyes," Dyes and Pigments, vol. 54, no. 2, pp. 141-146, 2002.

[59] R. L. McCreery, "Advanced carbon electrode materials for molecular electrochemistry," Chemical Reviews, vol. 108, no. 7, pp. 2646-2687, 2008.

[60] R. C. Engstrom, "Electrochemical pretreatment of glassy carbon electrodes," Analytical Chemistry, vol. 54, no. 13, pp. 2310-2314, 1982.

[61] M. A. Kulandainathan, K. Kiruthika, G. Christopher, K. F. Babu, A. Muthukumaran, and M. Noel, "Preparation of irondeposited graphite surface for application as cathode material during electrochemical vat-dyeing process," Materials Chemistry and Physics, vol. 112, no. 2, pp. 478-484, 2008.

[62] K. Rajeshwar, M. E. Osugi, W. Chanmanee et al., "Heterogeneous photocatalytic treatment of organic dyes in air and aqueous media," Journal of Photochemistry and Photobiology C, vol. 9, no. 4, pp. 171-192, 2008.

[63] P. A. Carneiro, M. E. Osugi, C. S. Fugivara, N. Boralle, M. Furlan, and M. V. B. Zanoni, "Evaluation of different electrochemical methods on the oxidation and degradation of Reactive Blue 4 in aqueous solution," Chemosphere, vol. 59, no. 3, pp. 431-439, 2005.

[64] Y. H. Lee and S. G. Pavlostathis, "Decolorization and toxicity of reactive anthraquinone textile dyes under methanogenic conditions," Water Research, vol. 38, no. 7, pp. 1838-1852, 2004.

[65] G. A. R. Oliveira, E. R. A. Ferraz, F. M. D. Chequer et al., "Chlorination treatment of aqueous samples reduces, but does not eliminate, the mutagenic effect of the azo dyes Disperse Red 1, Disperse Red 13 and Disperse Orange 1," Mutation Research, vol. 703, no. 2, pp. 200-208, 2010.

[66] P. A. Carneiro, G. A. Umbuzeiro, D. P. Oliveira, and M. V. B. Zanoni, "Assessment of water contamination caused by a mutagenic textile effluent/dyehouse effluent bearing disperse dyes," Journal of Hazardous Materials, vol. 174, no. 1-3, pp. 694-699, 2010.

[67] H. Zollinger, Color Chemistry-Synthesis, Propierties and Applications of Organic Dyes and Pigments, V.C.H, New York, NY, USA, 1991.

[68] C. C. I. Guaratini and M. V. B. Zanoni, "Textile dyes," Quimica Nova, vol. 23, no. 1, pp. 71-78, 2000.

[69] M. V. B. Zanoni, A. G. Fogg, J. Barek, and J. Zima, "Electrochemical investigations of reactive dyes; cathodic stripping voltammetric determination of anthraquinonebased chlorotriazine dyes at a hanging mercury drop electrode," Analytica Chimica Acta, vol. 349, no. 1-3, pp. 101109, 1997.

[70] P. A. Carneiro, M. E. Osugi, J. J. Sene, M. A. Anderson, and M. V. B. Zanoni, "Evaluation of color removal and degradation of a reactive textile azo dye on nanoporous $\mathrm{TiO}_{2}$ thin-film electrodes," Electrochimica Acta, vol. 49, no. 22-23, pp. 38073820, 2004.

[71] C. A. Martínez-Huitle and E. Brillas, "Decontamination of wastewaters containing synthetic organic dyes by electrochemical methods: a general review," Applied Catalysis B, vol. 87, no. 3-4, pp. 105-145, 2009.

[72] T. Robinson, G. McMullan, R. Marchant, and P. Nigam, "Remediation of dyes in textile effluent: a critical review on current treatment technologies with a proposed alternative," Bioresource Technology, vol. 77, no. 3, pp. 247-255, 2001.
[73] M. C. Gutiérrez and M. Crespi, "A review of electrochemical treatments for colour elimination," Journal of the Society of Dyers and Colourists, vol. 115, no. 11, pp. 342-345, 1999.

[74] M. M. Naim and Y. M. El Abd, "Removal and recovery of dyestuffs from dyeing wastewaters," Separation and Purification Methods, vol. 31, no. 1, pp. 171-228, 2002.

[75] A. B. dos Santos, F. J. Cervantes, and J. B. van Lier, "Review paper on current technologies for decolourisation of textile wastewaters: perspectives for anaerobic biotechnology," Bioresource Technology, vol. 98, no. 12, pp. 2369-2385, 2007.

[76] E. Forgacs, T. Cserháti, and G. Oros, "Removal of synthetic dyes from wastewaters: a review," Environment International, vol. 30, no. 7, pp. 953-971, 2004.

[77] C. A. Martínez-Huitle and S. Ferro, "Electrochemical oxidation of organic pollutants for the wastewater treatment: direct and indirect processes," Chemical Society Reviews, vol. 35, no. 12, pp. 1324-1340, 2006.

[78] S. Raghu and C. Ahmed Basha, "Chemical or electrochemical techniques, followed by ion exchange, for recycle of textile dye wastewater," Journal of Hazardous Materials, vol. 149, no. 2, pp. 324-330, 2007.

[79] N. Daneshvar, A. R. Khataee, A. R. Amani Ghadim, and M. H. Rasoulifard, "Decolorization of C.I. Acid Yellow 23 solution by electrocoagulation process: investigation of operational parameters and evaluation of specific electrical energy consumption (SEEC)," Journal of Hazardous Materials, vol. 148, no. 3, pp. 566-572, 2007.

[80] T. Bechtold, C. Mader, and J. Mader, "Cathodic decolourization of textile dyebaths: tests with full scale plant," Journal of Applied Electrochemistry, vol. 32, no. 9, pp. 943-950, 2002.

[81] D. Vaněrková, A. Sakalis, M. Holčapek, P. Jandera, and A. Voulgaropoulos, "Analysis of electrochemical degradation products of sulphonated azo dyes using high-performance liquid chromatography/tandem mass spectrometry," Rapid Communications in Mass Spectrometry, vol. 20, no. 19, pp. 2807-2815, 2006.

[82] C. Comninellis and C. Pulgarin, "Electrochemical oxidation of phenol for wastewater treatment using $\mathrm{SnO}_{2}$, anodes," Journal of Applied Electrochemistry, vol. 23, no. 2, pp. 108112, 1993.

[83] S. Stucki, R. Kötz, B. Carcer, and W. Suter, "Electrochemical waste water treatment using high overvoltage anodes Part II: anode performance and applications," Journal of Applied Electrochemistry, vol. 21, no. 2, pp. 99-104, 1991.

[84] A. M. Polcaro, S. Palmas, F. Renoldi, and M. Mascia, "On the performance of $\mathrm{Ti} / \mathrm{SnO}_{2}$ and $\mathrm{Ti} / \mathrm{PbO}_{2}$ anodes in electrochemical degradation of 2-chlorophenol for wastewater treatment," Journal of Applied Electrochemistry, vol. 29, no. 2, pp. 147-151, 1999.

[85] J. Feng, L. L. Houk, D. C. Johnson, S. N. Lowery, and J. J. Carey, "Electrocatalysis of anodic oxygen-transfer reactions: the electrochemical incineration of benzoquinone," Journal of the Electrochemical Society, vol. 142, no. 11, pp. 3626-3632, 1995.

[86] N. B. Tahar and A. Savall, "Electrochemical degradation of phenol in aqueous solution on bismuth doped lead dioxide: a comparison of the activities of various electrode formulations," Journal of Applied Electrochemistry, vol. 29, no. 3, pp. 277-283, 1999.

[87] P. Cañizares, M. Díaz, J. A. Domínguez, J. García-Gómez, and M. A. Rodrigo, "Electrochemical oxidation of aqueous phenol wastes on synthetic diamond thin-film electrodes," Industrial and Engineering Chemistry Research, vol. 41, no. 17, pp. 4187-4194, 2002. 
[88] L. Gherardini, P. A. Michaud, M. Panizza, C. Comninellis, and N. Vatistas, "Electrochemical oxidation of 4chlorophenol for wastewater treatment: definition of normalized current efficiency $(\varphi)$," Journal of the Electrochemical Society, vol. 148, no. 6, pp. D78-D82, 2001.

[89] D. Gandini, E. Mahé, P. A. Michaud, W. Haenni, A. Perret, and C. Comninellis, "Oxidation of carboxylic acids at borondoped diamond electrodes for wastewater treatment," Journal of Applied Electrochemistry, vol. 30, no. 12, pp. 1345-1350, 2000.

[90] M. Panizza, P. A. Michaud, G. Cerisola, and C. Comninellis, "Electrochemical treatment of wastewaters containing organic pollutants on boron-doped diamond electrodes: prediction of specific energy consumption and required electrode area," Electrochemistry Communications, vol. 3, no. 7, pp. 336-339, 2001.

[91] A. M. Polcaro, M. Mascia, S. Palmas, and A. Vacca, "Electrochemical degradation of diuron and dichloroaniline at BDD electrode," Electrochimica Acta, vol. 49, no. 4, pp. 649-656, 2004.

[92] M. Panizza and G. Cerisola, "Removal of colour and COD from wastewater containing acid blue 22 by electrochemical oxidation," Journal of Hazardous Materials, vol. 153, no. 1-2, pp. 83-88, 2008.

[93] M. Panizza and G. Cerisola, "Application of diamond electrodes to electrochemical processes," Electrochimica Acta, vol. 51, no. 2, pp. 191-199, 2005.

[94] C. Flox, S. Ammar, C. Arias, E. Brillas, A. V. Vargas-Zavala, and R. Abdelhedi, "Electro-Fenton and photoelectro-Fenton degradation of indigo carmine in acidic aqueous medium," Applied Catalysis B, vol. 67, no. 1-2, pp. 93-104, 2006.

[95] M. Panizza, A. Barbucci, R. Ricotti, and G. Cerisola, "Electrochemical degradation of methylene blue," Separation and Purification Technology, vol. 54, no. 3, pp. 382-387, 2007.

[96] N. Daneshvar, S. Aber, V. Vatanpour, and M. H. Rasoulifard, "Electro-Fenton treatment of dye solution containing Orange II: influence of operational parameters," Journal of Electroanalytical Chemistry, vol. 615, no. 2, pp. 165-174, 2008.

[97] M. Panizza and G. Cerisola, "Electro-Fenton degradation of synthetic dyes," Water Research, vol. 43, no. 2, pp. 339-344, 2009.

[98] M. Vilaseca, M. C. Gutiérrez, V. López-Grimau, M. LópezMesas, and M. Crespi, "Biological treatment of a textile effluent after electrochemical oxidation of reactive dyes," Water Environment Research, vol. 82, no. 2, pp. 176-182, 2010.

[99] M. Riera-Torres and M. C. Gutiérrez, "Colour removal of three reactive dyes by UV light exposure after electrochemical treatment," Chemical Engineering Journal, vol. 156, no. 1, pp. 114-120, 2010.

[100] V. López-Grimau and M. C. Gutiérrez, "Decolourisation of simulated reactive dyebath effluents by electrochemical oxidation assisted by UV light," Chemosphere, vol. 62, no. 1, pp. 106-112, 2006.

[101] F. H. Oliveira, M. E. Osugi, F. M. M. Paschoal, D. Profeti, P. Olivi, and M. V. B. Zanoni, "Electrochemical oxidation of an acid dye by active chlorine generated using Ti/ $/ \mathrm{Sn}_{(1-x)} \mathrm{Ir}_{x} \mathrm{O}_{2}$ electrodes," Journal of Applied Electrochemistry, vol. 37, no. 5, pp. 583-592, 2007.

[102] M. E. Osugi, K. Rajeshwar, E. R. A. Ferraz, D. P. de Oliveira, Â. R. Araújo, and M. V. B. Zanoni, "Comparison of oxidation efficiency of disperse dyes by chemical and photoelectrocatalytic chlorination and removal of mutagenic activity," Electrochimica Acta, vol. 54, no. 7, pp. 2086-2093, 2009.

[103] M. E. Osugi, G. A. Umbuzeiro, F. J. V. De Castro, and M. V. B. Zanoni, "Photoelectrocatalytic oxidation of remazol turquoise blue and toxicological assessment of its oxidation products," Journal of Hazardous Materials, vol. 137, no. 2, pp. 871-877, 2006.

[104] M. C. Gutierrez, V. Lopez-Grimau, M. Riera-Torres, M. Vilaseca, and M. M. Crespi, "Tratamiento electroquimico y reutilizacion de efluentes de tintura," Revista de Química Textil, vol. 191, pp. 40-46, 2009.

[105] L. Gomathi Devi, S. Girish Kumar, K. Mohan Reddy, and C. Munikrishnappa, "Photo degradation of Methyl Orange an azo dye by Advanced Fenton Process using zero valent metallic iron: influence of various reaction parameters and its degradation mechanism," Journal of Hazardous Materials, vol. 164, no. 2-3, pp. 459-467, 2009.

[106] Q. Zhang and Z. Zhang, "Preparation and characterization of nanocrystalline fe-doped $\mathrm{TiO}_{2}$ film on different substrates and its application in degrading dyeing water," Journal of Dispersion Science and Technology, vol. 30, no. 1, pp. 110-114, 2009.

[107] J. M. Peralta-Hernández, Y. Meas-Vong, F. J. Rodríguez, T. W. Chapman, M. I. Maldonado, and L. A. Godínez, "In situ electrochemical and photo-electrochemical generation of the fenton reagent: a potentially important new water treatment technology," Water Research, vol. 40, no. 9, pp. 1754-1762, 2006.

[108] W. G. Kuo, "Decolorizing dye wastewater with Fenton's reagent," Water Research, vol. 26, no. 7, pp. 881-886, 1992.

[109] F. Zhang, J. Zhao, T. Shen, H. Hidaka, E. Pelizzetti, and N. Serpone, " $\mathrm{TiO}_{2}$-assisted photodegradation of dye pollutants II. Adsorption and degradation kinetics of eosin in $\mathrm{TiO}_{2}$ dispersions under visible light irradiation," Applied Catalysis $B$, vol. 15, no. 1-2, pp. 147-156, 1998.

[110] C. G. Silva and J. L. Faria, "Photochemical and photocatalytic degradation of an azo dye in aqueous solution by UV irradiation," Journal of Photochemistry and Photobiology A, vol. 155, no. 1-3, pp. 133-143, 2003.

[111] C. Hachem, F. Bocquillon, O. Zahraa, and M. Bouchy, "Decolourization of textile industry wastewater by the photocatalytic degradation process," Dyes and Pigments, vol. 49, no. 2, pp. 117-125, 2001.

[112] G. A. Epling and C. Lin, "Photoassisted bleaching of dyes utilizing $\mathrm{TiO}_{2}$ and visible light," Chemosphere, vol. 46, no. 4, pp. 561-570, 2002.

[113] Y. B. Xie and Y. B. X. Z. Li, "Interactive oxidation of photoelectrocatalysis and electr-Fenton for azo dye degradation using $\mathrm{TiO}_{2}$-Ti mesh and reticulated vitreous carbon electrodes," Materials Chemistry and Physics, vol. 95, no. 1, pp. 39-50, 2006.

[114] A. Duran, J. M. Monteagudo, and J. M. E. Amores, "Solar photo-Fenton degradation of reactive blue 4 in a CPC reactor," Applied Catalysis B, vol. 80, no. 1-2, pp. 42-50, 2008.

[115] S. Figueroa, L. Vazquez, and A. Alvarez-Gallegos, "ecolorizing textile wastewater with Fenton's reagent electrogenerated with solar photovoltaic cell," Water Research, vol. 43, no. 2, pp. 283-294, 2009.

[116] M. Sala, Dissertation: Aplicació de Techniques Electroquimiques i Fotoelectroquímiques per la Degradació de Compostos poc Biodegradables en Efluents Industrials Tèxtils, UPC, 2012. 


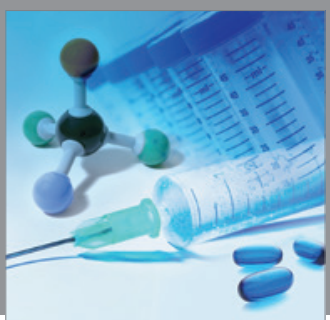

International Journal of

Medicinal Chemistry

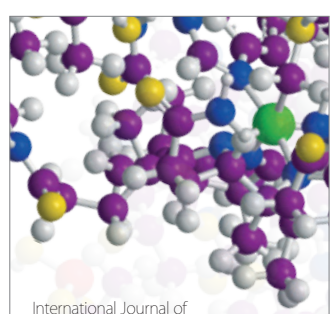

Carbohydrate Chemistry

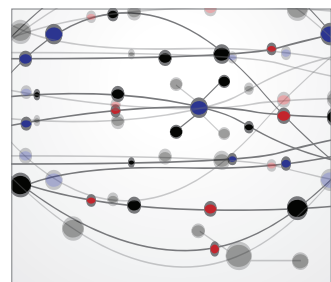

The Scientific World Journal
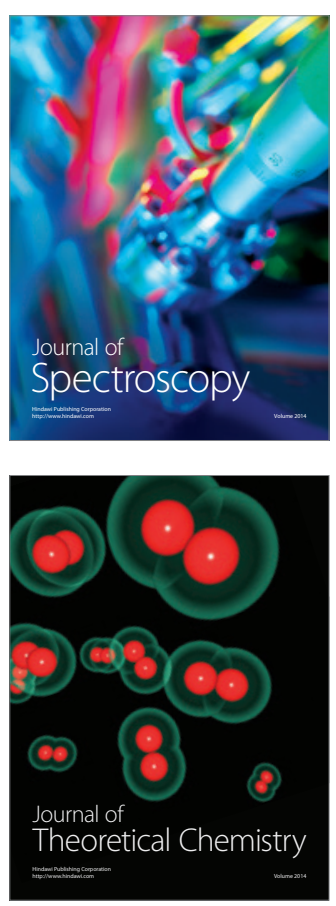
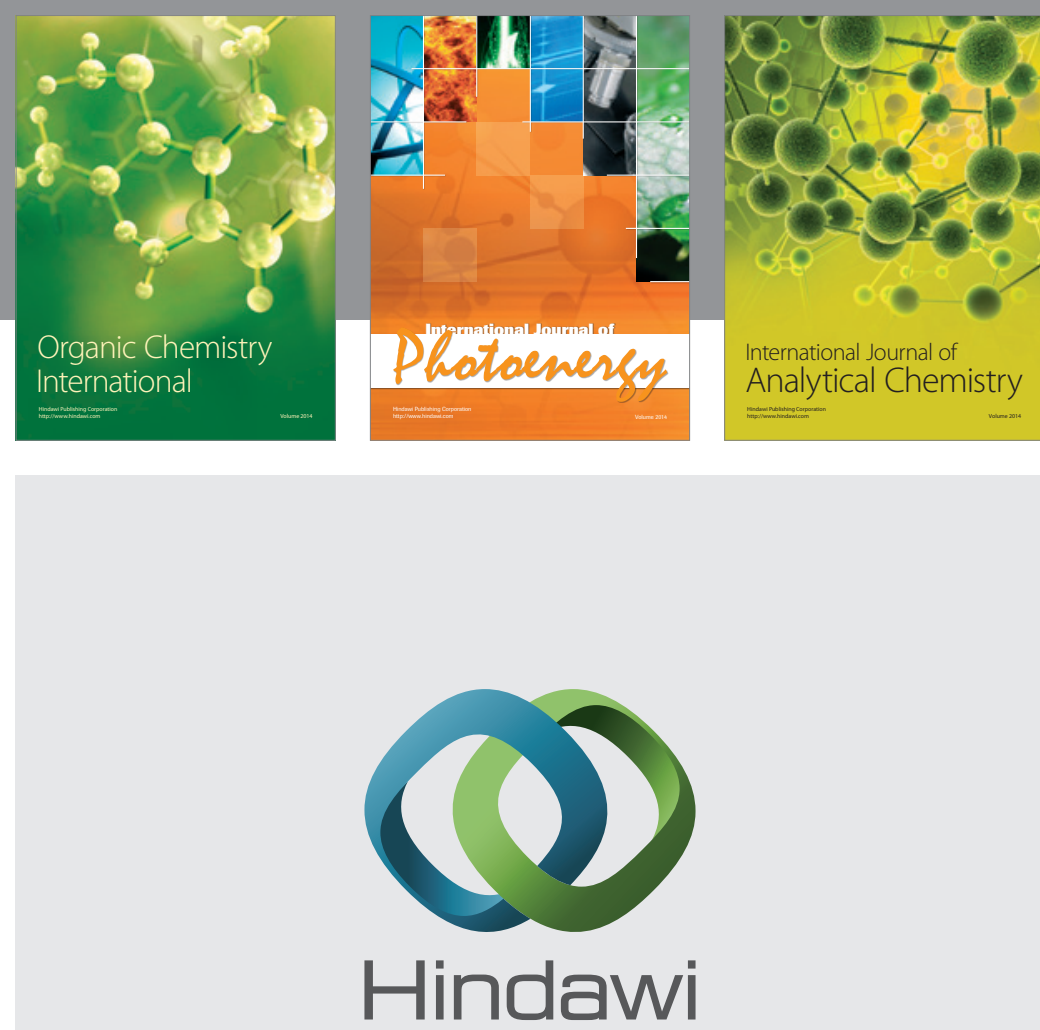

Submit your manuscripts at

http://www.hindawi.com
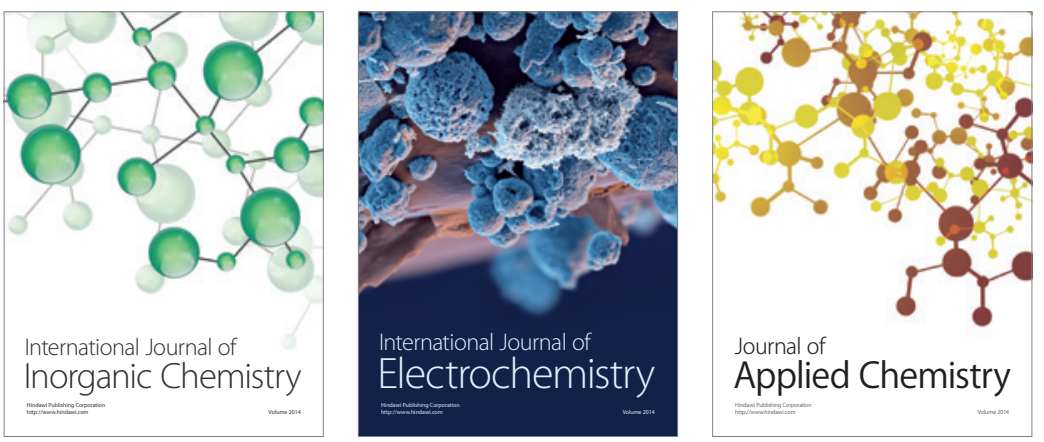

Journal of

Applied Chemistry
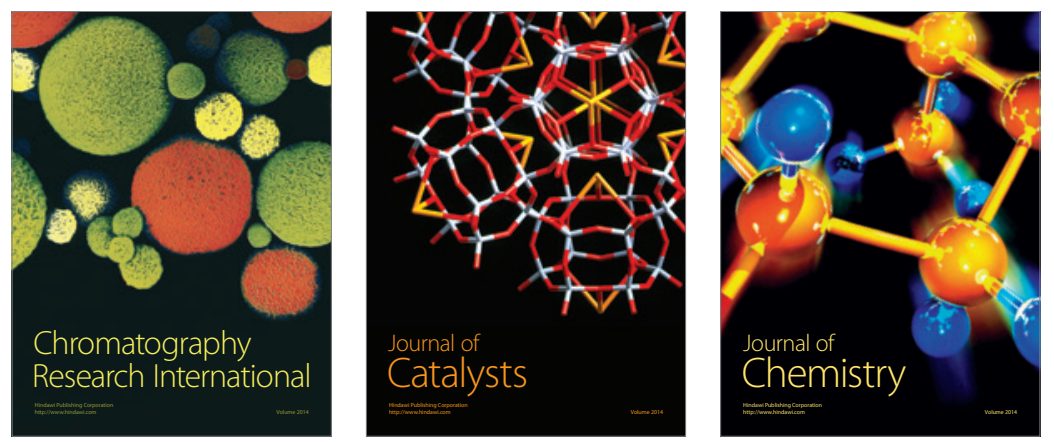
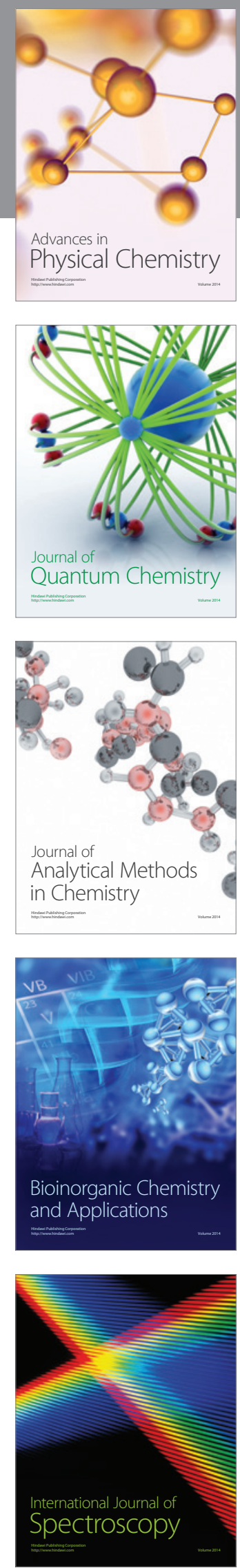